\title{
Echocardiographic evaluation of propranolol therapy for mitral valve prolapse ${ }^{1}$
}

\author{
Roger A. Winkle, Daniel J. Goodman, and Richard L. Popp \\ From Cardiology Division, Stanford University School of Medicine, Stanford, California, U.S.A.
}

This study evaluates the effect of propranolol on the echocardiogram of 8 patients with late systolic mitral valve prolapse. Echocardiograms were performed with the patients on no medication and again while on oral propranolol therapy. Propranolol caused a statistically significant increase in left ventricular volume; however, neither the echocardiographic pattern nor the timing of mitral valve prolapse was altered by propranolol. These findings suggest that factors in addition to left ventricular volume play a role in regulating valvular dysfunction in this condition.

Changes in left ventricular volume appear to be important in changing the timing and extent of mitral valve prolapse (Fontana et al., 1970). Passive tilting, which decreases the left ventricular volume, causes greater prolapse, as determined by angiography (Fontana et al., 1975). Amyl nitrite inhalation, which also decreases left ventricular volume, causes earlier systolic prolapse of the mitral valve compared to control observations, and may even transform the echocardiographic mitral prolapse pattern from late systolic to holosystolic (Winkle, Goodman, and Popp, 1975; Dillon et al., 1971). Propranolol, which increases resting left ventricular end-diastolic volume (Helfant, Herman, and Gorlin, 1971), has been reported to diminish or abolish some of the auscultatory findings in patients with mitral prolapse, suggesting that an increase in left ventricular volume may improve the valvular dysfunction (Zeilenga and Criley, 1973). The present study evaluates the effect of propranolol on the timing and pattern of echocardiographic mitral valve prolapse, in an attempt to determine whether or not propranolol alters the basic valvular $a b-$ normality in this condition.

\section{Patients and methods}

Eight patients, 7 women and one man, seen at the Stanford University Medical Center, were studied after informed consent had been obtained. All 8 patients had late systolic mitral valve prolapse on echocardiogram. No patient had evidence of heart disease other than the

Received 25 July 1975.

${ }^{1}$ This work was supported in part by NIH grants. mitral valve abnormality, and all were in sinus rhythm. Seven of the 8 patients had clicks or murmurs (Table), and all 8 had symptoms or arrhythmias characteristic of the mitral valve prolapse syndrome.

Echocardiograms were performed while the patients were taking no cardiac medication and repeated during oral propranolol therapy, which was given in an effort to control symptoms or arrhythmias. The echocardiograms were obtained with an Ekoline 20A Smith-Kline ultrasonoscope, using a $2.25 \mathrm{mHz} 0.5 \mathrm{~cm}$ diameter transducer, with beam collimation to $5 \mathrm{~cm}$ depth. Patients were supine and turned approximately $30^{\circ}$ into the left lateral decubitus position, and the mitral valve was recorded with the transducer positioned perpendicular to the chest wall in the third or fourth intercostal space at the left sternal border. Left ventricular volumes were obtained by tilting the transducer slightly inferiorly and laterally to record the maximum left ventricular dimension, at a level just below the free edge of the mitral valve. Simultaneous phonocardiograms were recorded at the cardiac apex in some patients, using a Maico contact microphone filtered to display frequencies of 120 to $500 \mathrm{~Hz}$. A permanent strip-chart reçording of this information was made at a paper speed of 50 or $75 \mathrm{~mm} / \mathrm{s}$, using an Electronics for Medicine DR8 recorder.

\section{Measurements}

From these recordings, various points were identified and dimensions and time intervals measured. The onset of abrupt posterior movement of the posterior mitral valve leaflet during systole was termed the 'P' (prolapse) point (Fig. 1), as described previously (Winkle et al., 1975). The ' $C$ ' point of apparent mitral valve closure and ' $D$ ' point of apparent mitral leaflet separation at opening were identified as described by Edler et al. (1961). In those patients in whom a clear $D$ point could not be 
TABLE Summary of effect of propranolol on echocardiogram of patients with late systolic mitral valve prolapse

\begin{tabular}{|c|c|c|c|c|c|c|c|c|}
\hline $\begin{array}{l}\text { Case } \\
\text { No. }\end{array}$ & & $\begin{array}{l}\text { Heart } \\
\text { rate } \\
(b / \mathrm{min})\end{array}$ & $\begin{array}{l}\text { Duration } \\
\text { of systole } \\
(C-D) \text { (ms) }\end{array}$ & $\begin{array}{l}\text { Duration } \\
\text { of prolapse } \\
(P-D) \text { (ms) }\end{array}$ & $\begin{array}{l}\text { Prolapse } \\
\text { fraction } \\
(P-D / C-D)\end{array}$ & $\begin{array}{l}\text { LVEDD } \\
(\mathrm{cm})\end{array}$ & $\begin{array}{l}\text { LVEDV } \\
(m l)\end{array}$ & $\begin{array}{l}\text { LVESD } \\
(\mathrm{cm})\end{array}$ \\
\hline 1 & $\begin{array}{l}\text { Control } \\
\text { Propranolol } \\
320 \mathrm{mg} / \text { day }\end{array}$ & $\begin{array}{l}60 \\
50\end{array}$ & $\begin{array}{l}380 \\
420\end{array}$ & $\begin{array}{l}210 \\
250\end{array}$ & $\begin{array}{l}0.55 \\
0.60\end{array}$ & $\begin{array}{l}4 \cdot 8 \\
5 \cdot 0\end{array}$ & $\begin{array}{l}111 \\
125\end{array}$ & $\begin{array}{l}3.0 \\
3.0\end{array}$ \\
\hline 2 & $\begin{array}{l}\text { Control } \\
\text { Propranolol } \\
80 \mathrm{mg} / \text { day }\end{array}$ & $\begin{array}{l}62 \\
58\end{array}$ & $\begin{array}{l}410 \\
430\end{array}$ & $\begin{array}{l}250 \\
250\end{array}$ & $\begin{array}{l}0.61 \\
0.58\end{array}$ & $\begin{array}{l}4.8 \\
5 \cdot 5\end{array}$ & $\begin{array}{l}111 \\
166\end{array}$ & $\begin{array}{l}2 \cdot 8 \\
3 \cdot 4\end{array}$ \\
\hline 3 & $\begin{array}{l}\text { Control } \\
\text { Propranolol } \\
160 \mathrm{mg} / \text { day }\end{array}$ & $\begin{array}{l}68 \\
56\end{array}$ & $\begin{array}{l}400 \\
420\end{array}$ & $\begin{array}{l}270 \\
270\end{array}$ & $\begin{array}{l}0.67 \\
0.64\end{array}$ & $\begin{array}{l}5 \cdot 8 \\
6 \cdot 1\end{array}$ & $\begin{array}{l}195 \\
227\end{array}$ & $\begin{array}{l}3 \cdot 6 \\
3 \cdot 7\end{array}$ \\
\hline 4 & $\begin{array}{l}\text { Control } \\
\text { Propranolol } \\
160 \mathrm{mg} / \text { day }\end{array}$ & $\begin{array}{l}69 \\
63\end{array}$ & $\begin{array}{l}370 \\
370\end{array}$ & $\begin{array}{l}250 \\
250\end{array}$ & $\begin{array}{l}0.68 \\
0.68\end{array}$ & $\begin{array}{l}4 \cdot 4 \\
4 \cdot 6\end{array}$ & $\begin{array}{l}85 \\
97\end{array}$ & $\begin{array}{l}2 \cdot 7 \\
2 \cdot 7\end{array}$ \\
\hline 5 & $\begin{array}{l}\text { Control } \\
\text { Propranolol } \\
160 \mathrm{mg} / \text { day }\end{array}$ & $\begin{array}{l}80 \\
56\end{array}$ & $\begin{array}{l}360 \\
400\end{array}$ & $\begin{array}{l}190 \\
190\end{array}$ & $\begin{array}{l}0.53 \\
0.49\end{array}$ & $\begin{array}{l}5 \cdot 6 \\
5 \cdot 8\end{array}$ & $\begin{array}{l}176 \\
195\end{array}$ & $\begin{array}{l}3 \cdot 4 \\
4 \cdot 1\end{array}$ \\
\hline 6 & $\begin{array}{l}\text { Control } \\
\text { Propranolol } \\
80 \mathrm{mg} / \text { day }\end{array}$ & $\begin{array}{l}80 \\
54\end{array}$ & $\begin{array}{l}340 \\
440\end{array}$ & $\begin{array}{l}210 \\
310\end{array}$ & $\begin{array}{l}0.62 \\
0.70\end{array}$ & $\begin{array}{l}4 \cdot 6 \\
4 \cdot 9\end{array}$ & $\begin{array}{r}97 \\
118\end{array}$ & $\begin{array}{l}2 \cdot 8 \\
2 \cdot 9\end{array}$ \\
\hline 7 & $\begin{array}{l}\text { Control } \\
\text { Propranolol } \\
120 \mathrm{mg} / \text { day }\end{array}$ & $\begin{array}{l}79 \\
73\end{array}$ & $\begin{array}{l}370 \\
380\end{array}$ & $\begin{array}{l}220 \\
230\end{array}$ & $\begin{array}{l}0.59 \\
0.61\end{array}$ & $\begin{array}{l}6.0 \\
6.4\end{array}$ & $\begin{array}{l}216 \\
261\end{array}$ & $\begin{array}{l}4 \cdot 3 \\
4 \cdot 6\end{array}$ \\
\hline 8 & $\begin{array}{l}\text { Control } \\
\text { Propranolol } \\
160 \mathrm{mg} / \text { day }\end{array}$ & $\begin{array}{l}68 \\
51\end{array}$ & $\begin{array}{l}360 \\
370\end{array}$ & $\begin{array}{l}180 \\
200\end{array}$ & $\begin{array}{l}0.50 \\
0.54\end{array}$ & $\begin{array}{l}5 \cdot 0 \\
5 \cdot 0\end{array}$ & $\begin{array}{l}125 \\
125\end{array}$ & $\begin{array}{l}3 \cdot 1 \\
3 \cdot 1\end{array}$ \\
\hline Mean & $\begin{array}{l}\text { Control } \\
\text { Propranolol } \\
\text { P }\end{array}$ & $\begin{array}{c}70 \cdot 8 \pm 8.0 \\
56.9 \pm 7 \cdot 7 \\
<0.005\end{array}$ & $\begin{array}{l}373 \pm 23 \\
404 \pm 28 \\
<0.05\end{array}$ & $\begin{array}{l}222 \pm 32 \\
244 \pm 38 \\
N S\end{array}$ & $\begin{array}{l}0.59 \pm 0.06 \\
0.60 \pm 0.07 \\
N S\end{array}$ & $\begin{array}{l}5.12 \pm 0.60 \\
5.41 \pm 0.64 \\
<0.01\end{array}$ & $\begin{array}{c}140 \pm 49 \\
164 \pm 59 \\
<0.01\end{array}$ & $\begin{array}{l}3.21 \pm 0.54 \\
3.44 \pm 0.66 \\
<0.07\end{array}$ \\
\hline
\end{tabular}

LVEDD and LVEDV, left ventricular end-diastolic dimension and volume; LVESD and LVESV, left ventricular end-systolic dime्gnsion and volume; MSC, mid-systolic click; LSM, late systolic murmur; NS, not statistically significant.

determined because of the prolapse, $D$ was defined as the intersection of a line extended through points $C$ and $P$, with the anterior motion of the mitral valve leaflet at end-systole. From these reference points (Fig. 1), the following time intervals were measured: the duration of systole (C-D), the pre-prolapse interval (C-P), and the duration of prolapse (P-D). The fraction of systole occupied by prolapse (prolapse fraction) was expressed as the ratio $\frac{\mathrm{P}-\mathrm{D}}{\mathrm{C}-\mathrm{D}}$.

Left ventricular end-diastolic dimension and left ventricular end-systolic dimension were defined as the maximal and minimal separation of the left interventricular septal and left ventricular posterior endocardial echoes. The left ventricular end-diastolic volume (LVEDV) and end-systolic volume (LVESV) were determined by cubing these dimensions (Popp and Harrison, 1970). Stroke volume (SV) and ejection fraction (EF) were derived using the following equations:

$$
\begin{aligned}
& \text { SV }=\text { LVEDV - LVESV } \\
& \mathbf{E F}=\frac{\text { SV }}{\text { LVEDV }}
\end{aligned}
$$

All measurements were averaged over 5 beats to minimize respiratory variation.

Statistical analysis was performed using the twotailed $t$ test for matched pairs, comparing control and propranolol data.

\section{Results}

The Table summarizes the results of this study. Propranolol, in doses ranging from $80 \mathrm{mg}$ to $320 \mathrm{mg}$ per day, decreased the resting heart rate in all patients (Fig. 2). The decrease in mean heart rate from $70.8 \pm 8.0$ to $56.9 \pm 7.7$ beats per minute $(\mathrm{P}<0.005)$ (Fig. 2) suggests propranolol produced a physiological degree of beta-adrenergic blockade in these patients.

\section{Ventricular volume}

Propranolol increased the left ventricular enddiastolic dimension from a mean value $( \pm S D)$ of $5.12 \pm 0.60$ to $5.41 \pm 0.64 \mathrm{~cm}(P<0.01)$, with an associated increase in mean left ventricular enddiastolic volume from $140 \pm 49$ to $164 \pm 59 \mathrm{ml}$ $(P<0.01)$ (Fig. 3). Propranolol also increased the left ventricular end-systolic dimension and volume, but these changes were of only borderline statistical significance $(P<0.07)$. Propranolol increased the stroke volume from $103 \pm 32$ to $120 \pm 35 \mathrm{ml} /$ beat $(P<0.03)$; however, it did not change the calculated ejection fraction (Table). 


\begin{tabular}{lcll}
$\begin{array}{l}\text { LVESV } \\
(m l)\end{array}$ & $\begin{array}{l}S V \\
(m l)\end{array}$ & $\begin{array}{l}\text { Ejection } \\
\text { fraction }\end{array}$ & $\begin{array}{l}\text { Phonocardiographic } \\
\text { findings }\end{array}$ \\
\hline 27 & 84 & 0.76 & MSC \\
27 & 98 & 0.78 & MSC \\
22 & 89 & 0.80 & MSC_LSM \\
39 & 127 & 0.77 & Not done \\
47 & 148 & 0.76 & LSM \\
51 & 176 & 0.78 & Not done \\
20 & & 0.76 & LSM \\
20 & 65 & 0.79 & LSM \\
39 & 77 & 0.78 & MSC \\
69 & 137 & 0.65 & Not done \\
22 & 126 & 0.77 & MSC \\
24 & 75 & 0.80 & MSC \\
80 & 94 & 0.63 & Normal \\
97 & 136 & 0.63 & Normal \\
30 & 164 & 0.76 & MSC-?LSM \\
30 & 95 & 0.76 & MSC \\
$35.9 \pm 20.1$ & $103 \pm 32$ & $0.75 \pm 0.05$ & \\
$44.6 \pm 26.6$ & $120 \pm 35$ & $0.75 \pm 0.07$ & \\
$<0.07$ & $<0.03$ & NS & \\
\hline & & &
\end{tabular}

\section{Echocardiographic pattern and timing of mitral valve prolapse}

While taking propranolol, all 8 patients retained the late systolic pattern of mitral valve prolapse on the echocardiogram. Propranolol did not decrease the apparent redundancy of the mitral valve characterized by multiple echoes seen during systole, nor did it appear to lessen the degree of prolapse toward the left atrium (Fig. 1, 4, and 5).

Propranolol did not influence the timing of echocardiographic mitral valve prolapse. With propranolol there was a slower heart rate, accompanied by an increase in the duration of systole (C-D) $(P<0.05)$, reflecting slight increases in both the pre-prolapse interval (C-P) and the duration of prolapse (P-D). However, neither of the latter changes alone achieved statistical significance. Propranolol did not change the prolapse fraction (P-D) $/($ C-D) (Fig. 6) and thus did not alter the relative timing of echocardiographic mitral valve prolapse.

\section{Discussion}

Left ventricular volume changes seem important in determining the onset and extent of mitral valve prolapse. Decreased left ventricular volume is associated with an earlier onset (Winkle et al., 1975) and a greater amount (Fontana et al., 1975) of mitral valve prolapse. Presumably, increased left ventricular volume produces opposite effects; however, this has never been carefully documented. Recent studies suggest that factors other than left ventricular volume may influence the dynamics of valve prolapse. Clicks, and presumably mitral valve prolapse, occur earlier in the first systole after termination of rapid atrial pacing (Towne et al., 1973). Since left ventricular volume increases with the long pause after termination of pacing, one would expect the clicks to occur later, rather than earlier, in systole. In this context, an effect of increased contractility and/or decreased afterload on valve prolapse dynamics were postulated to account for the earlier occurrence of clicks. It is not known whether contractility or afterload changes alone can alter the timing of mitral valve prolapse. Phenylephrine increases afterload, but usually does not change the timing of clicks (Barlow et al., 1968), though they may occur later in systole (LeWinter et al., 1974).

Complete understanding of the factors influencing mitral valve prolapse is desirable for optimal clinical management of these patients. For example, most patients with mitral regurgitation respond to afterload reduction with a decrease in left ventricular volume and a reduction in the amount of mitral valve regurgitation (Goodman et al., 1974). Patients with mitral regurgitation associated with mitral valve prolapse could, theoretically, show a paradoxical response with an increase in the mitral prolapse and a worsening of the regurgitation. A single patient reported by Bittar and Sosa (1968) did show an increase in angiographically demonstrated mitral regurgitation during amyl nitrite inhalation. This case demonstrates that such a paradoxical response can occur. If increased contractility can cause earlier prolapse, the administration of inotropic agents could potentially worsen valvular dysfunction. The clinical significance of such paradoxical responses and their frequency is unknown at the present time.

In this study propranolol did not alter the timing or echocardiographic pattern of mitral valve prolapse, despite the fact that it caused a slight increase in left ventricular end-diastolic volume. This lack of effect may be partially related to the relatively small increase in left ventricular dimensions after propranolol. In a previous study (Winkle et al., 1975), we demonstrated that amyl nitrite, which causes earlier prolapse and occasionally converts late systolic prolapse to holosystolic prolapse, decreased the left ventricular end-diastolic di- 


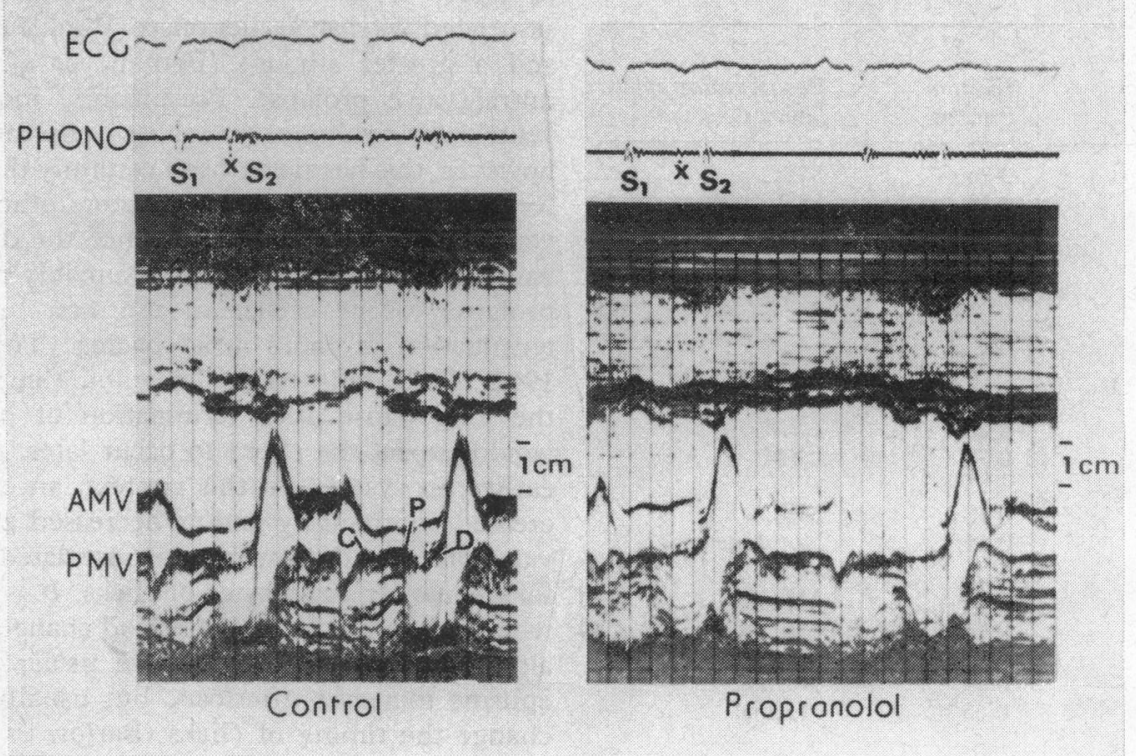

FIG. 1 Representative control and propranolol echocardiogram (Case 8). The $C, P$, and $D$ points are labelled in the control echocardiogram. Except for the slower heart rate, the echocardiograms are similar. Behind the dominant, labelled echo, faint echoes characteristic of mitral valve prolapse can be seen in the left atrium, both before and after propranolol.

mension by an average of $5.5 \mathrm{~mm}$. Propranolol caused an average increase in this dimension of only $2.9 \mathrm{~mm}$, approximately half the change produced by amyl nitrite. This smaller change, relative to the presumed fixed length of the chordae tendineae, may be insufficient to produce a detectable change in the timing or pattern of mitral valve prolapse. However, propranolol also produces changes in heart rate, systemic vascular resistance, arterial pressure, left ventricular filling pressure, cardiac output, and myocardial contractility. The lack of effect of propranolol in these patients, despite a modest increase in left ventricular volume, suggests that some of these factors may influence valve dynamics in patients with mitral valve prolapse.

Although this is an echocardiographic and not a haemodynamic study, it suggests that propranolol does not cause dramatic changes in the valvular dysfunction of mitral valve prolapse. We have performed left ventricular angiograms before and after intravenous propranolol administration in a single patient with late systolic prolapse and could detect no effect on the mitral valve prolapse. Shappell et al. (1973) also reported a single patient in whom propranolol did not affect the degree of mitral valve prolapse on angiography. Therefore, on the basis of current knowledge, we conclude that the ability of propranolol to relieve symptoms or abolish serious arrhythmias in some patients with mitral valve prolapse is probably not related to anatomical improvement of the valve dysfunction.

\section{References}

Barlow, J. B., Bosman, C. K., Pocock, W. A., and Marchand, P. (1968). Late systolic murmurs and non-ejection ('midlate') systolic clicks. An analysis of 90 patients. British Heart fournal, 30, 203.

Bittar, N., and Sosa, J. A. (1968). The billowing mitral valve leaflet. Report on fourteen patients. Circulation, 38, 763.

Dillon, J. C., Haine, C. L., Chang, S., and Feigenbaum, H. (1971). Use of echocardiography in patients with prolapsed mitral valve. Circulation, 43, 503.

Edler, I., Gustafson, A., Karlefors, T., and Christensson, B.( 1961). Ultrasoundcardiography. Acta Medica Scandinavica, Suppl. 370.

Fontana, M. E., Pence, H. L., Leighton, R. F., and Wooley, C. F. (1970). The varying clinical spectrum of the systolic click-late systolic nurmur syndrome. A postural auscultatory phenomenon. Circulation, 41, 807.

Fontana, M. E., Wooley, C. F., Leighton, R. F., and Lewis. R. P. (1975). Postural changes in left ventricular and mitral valvular dynamics in the systolic click - late systolic murmur syndrome. Circulation, 51, 165. 


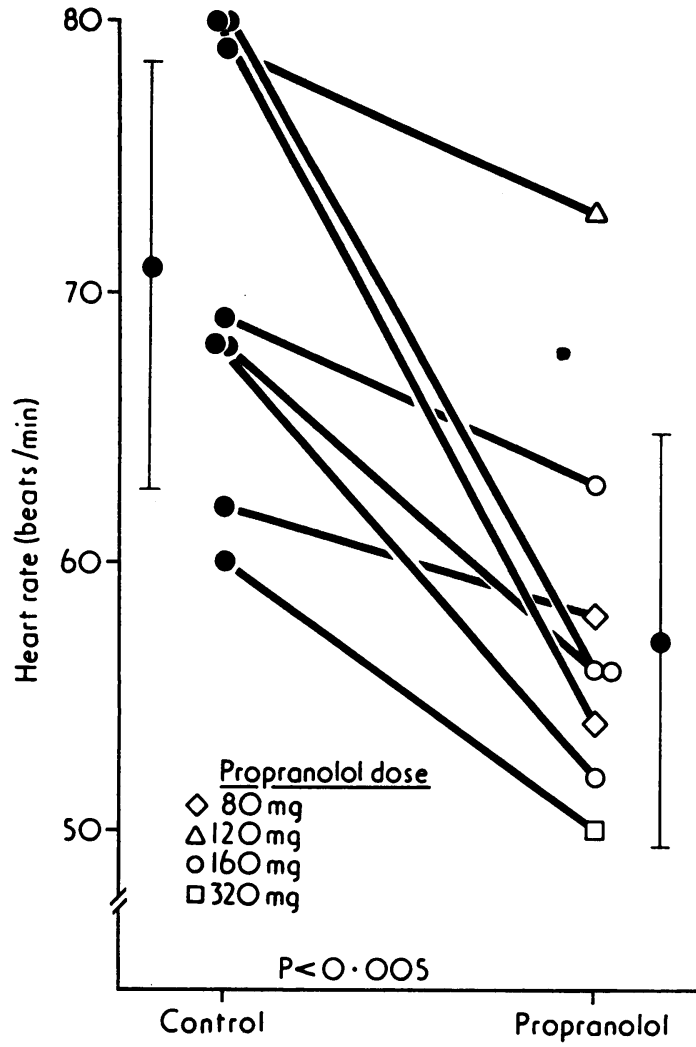

FIG. 2 The reduction in resting heart rate after propranolol administration is demonstrated for the patients in this study. This reduction was significant at the 0.005 level.

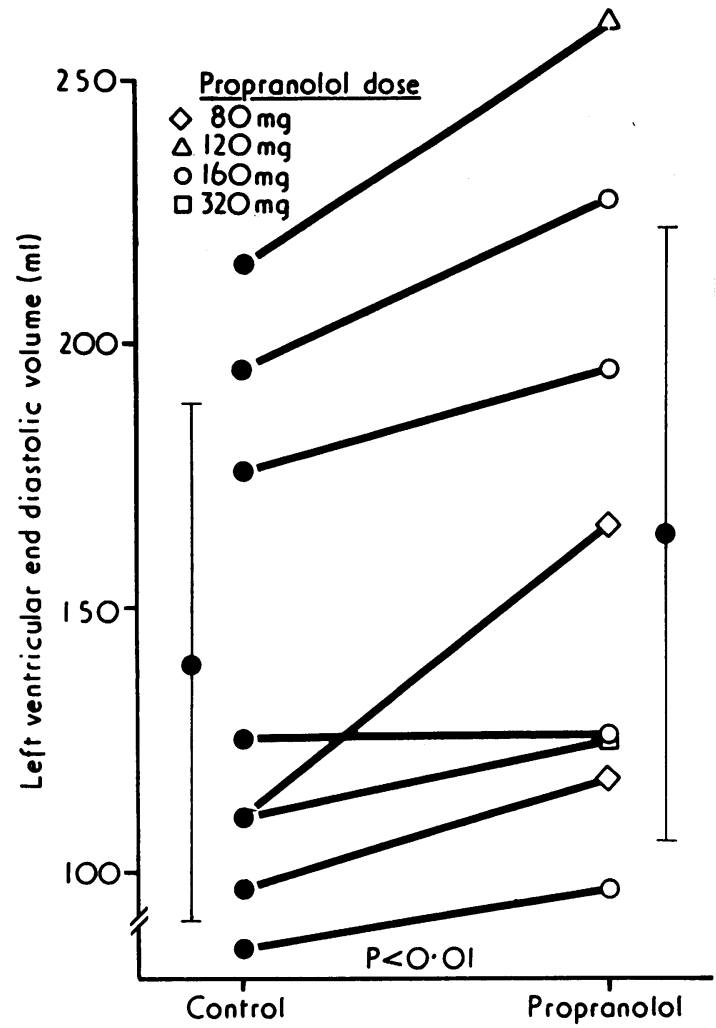

FIG. 3 The increase in left ventricular enddiastolic volume while the patient was taking propranolol is illustrated. This increase in volume probably reflects compensatory changes to maintain cardiac output at the slower heart rate.

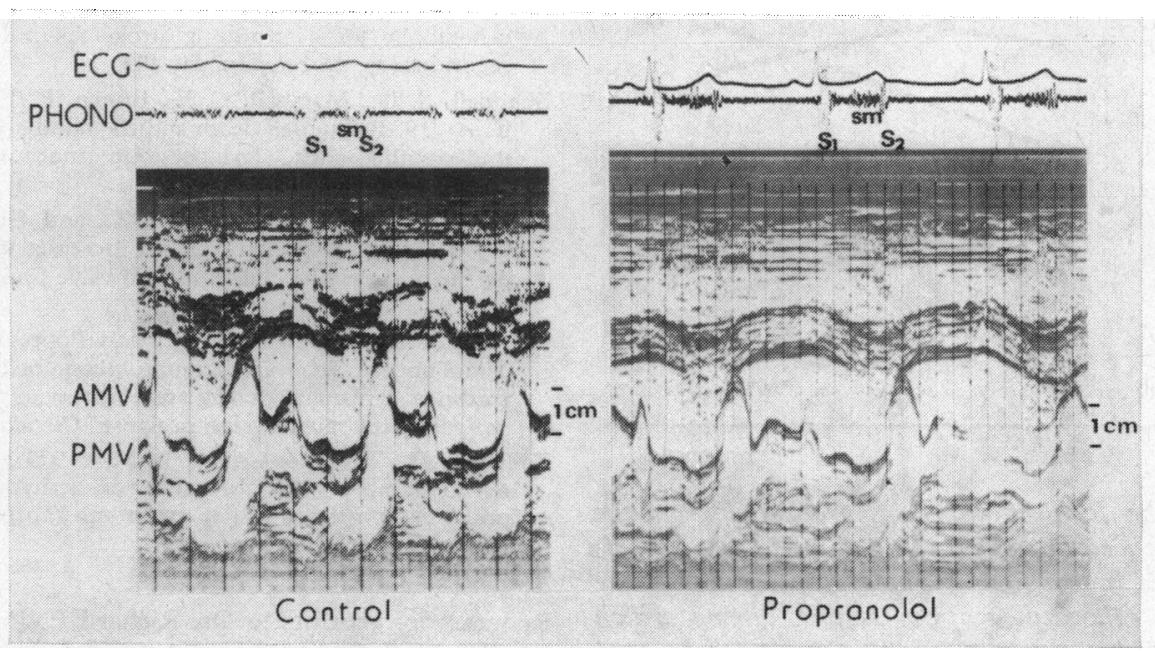

FIG. 4 Control and propranolol echocardiograms from Case 4. There is no apparent change in the echocardiographic pattern and timing of mitral valve prolapse. A late systolic murmur is seen on both phonocardiograms. 


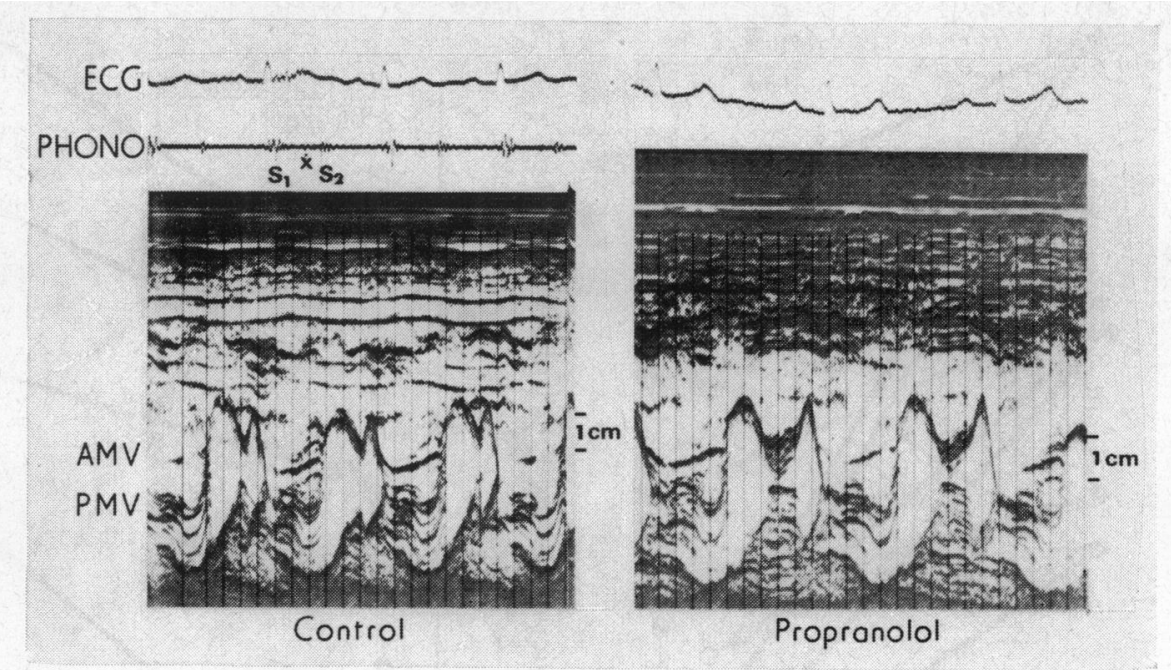

FI G. 5 Control and propranolol echocardiograms from Case 5. As in Fig. 1 and 4, propranolol does not appear to have altered echocardiographic mitral prolapse or the striking redundancy, appearing as multiple mitral valve echoes during systole, that this patient demonstrates.

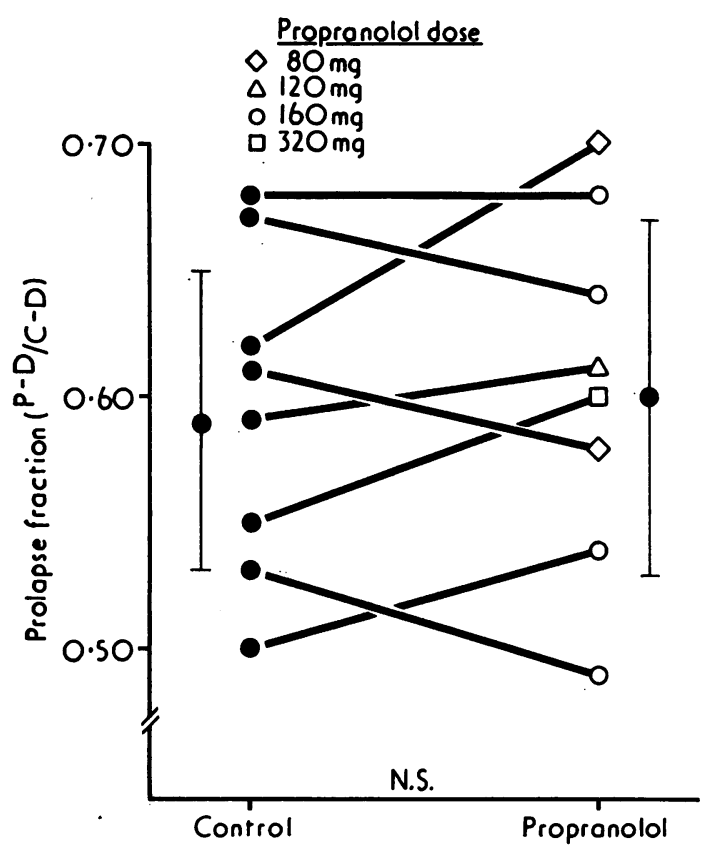

FIG. 6 The lack of effect of propranolol on the timing of echocardiographic mitral valve prolapse is demonstrated in this figure. The prolapse fraction, the fraction of echocardiographic systole during which the mitral valve is prolapsed, was unaltered by oral propranolol therapy.
Goodman, D. J., Rossen, R. M., Holloway, E. L., Alderman, E. L., and Harrison, D. C. (1974). Effect of nitroprusside on left ventricular dynamics in mitral reguritation. Circulation, 50, 1025.

Helfant, R. H., Herman, M. V., and Gorlin, R. (1971) Abnormalities of left ventricular contraction induced by beta adrenergic blockage. Circulation, 43, 641.

LeWinter, M. M., Hoffman, J. R., Shell, W. E., Karliner, J. S., and O'Rourke, R. A. (1974). Phenylephrineinduced atypical chest pain in patients with prolapsing mitral valve leaflets. American fournal of Cardiology, 34, 12.

Popp, R. L., and Harrison, D. C. (1970). Ultrasonic cardiac echography for determining stroke volume and valvular regurgitation. Circulation, 41, 493.

Shappell, S. D., Marshall, C. E., Brown, R. E., and Bruce, T. A. (1973). Sudden death and the familial occurrence of mid-systolic click, late systolic murmur syndrome. Circulation, 48, 1128.

Towne, W., Loeb, H., Sinno, M. Z., and Gunnar, R. M. (1973). Effect of pacing induced increases in cycle length on the mid-systolic click of mitral valve prolapse. Circulation, 47 and 48, Suppl. 4, 224.

Winkle, R. A., Goodman, D. J., and Popp, R. L. (1975). Simultaneous echocardiographic-phonocardiographic recordings at rest and during amyl nitrite administration in patients with mitral valve prolapse. Circulation, 51, 522.

Zeilenga, D. W., and Criley, J. M. (1973). Mitral valve dysfunction-a possible cause of arrhythmias in the prolapsed posterior leaflet syndrome (abstract). Clinical Research, 21, 243.

Requests for reprints to Dr. Richard L. Popp, Cardiology Division, Stanford University School of Medicine, Stanford, California 94305, U.S.A. 